\title{
Aneurisma de la Arteria esplénica. A propósito de un caso
}

\author{
Aneurysm of the splenic artery. About a case \\ ${ }^{\star}$ Dennis Cabral ${ }^{1,}{ }^{\star *}$ Robert Ayala ${ }^{1},{ }^{\star *}$ Jorge Ruiz Diaz ${ }^{2},{ }^{\star * *}$ Michel Kostinchok ${ }^{1}$
}

1. Hospital Nacional de Itauguá, Cirugía General. Paraguay

2. Hospital Nacional de Itauguá, Cirugía Vascular. Paraguay

\section{RESUMEN}

En la patología abdominal vascular, los aneurismas abdominales localizados en la arteria esplénica son de infrecuente aparición. Siendo mayoritariamente asintomáticos, cuando presentan síntomas pueden ser inespecíficos o presentarse como abdomen agudo hemorrágico por rotura del aneurisma a retroperitoneo u órganos vecinos. Se presentará a continuación un caso de un paciente con aneurisma de arteria esplénica y se revisara la literatura con el objetivo de mostrar las alternativas diagnósticas y terapéuticas.

Palabras clave: Aneurisma, arteria esplénica, laparoscopia.

\section{ABSTRACT}

In vascular abdominal pathology, abdominal aneurysms located in the splenic artery are infrequent. Being mostly asymptomatic, when they present symptoms they can be nonspecific or present as acute hemorrhagic abdomen due to rupture of the aneurysm to the retroperitoneum or neighboring organs. A case of a patient with splenic artery aneurysm will be presented below and the literature will be reviewed with the aim of showing diagnostic and therapeutic alternatives.

Keywords: Aneurysm, splenic artery, laparoscopy.

\section{INTRODUCCIÓN}

Lo aneurismas de la Arteria esplénica son responsables de hasta del $60 \%$ de todos los aneurismas viscerales, y es el tercer aneurisma abdominal más común, después de los de aorta y de las $\operatorname{arterias~ilíaca~}^{(1)}$.

Se lo define como una dilatación anormal de la arteria esplénica mayor a $1 \mathrm{~cm}$ de diámetro. Se presenta mayoritariamente en mujeres, con edad mayor a 55 años y la relación es de 4:1.

Aunque la patogenia no está completamente entendida, los factores de riesgo incluyen arteriosclerosis, traumatismos, hipertensión portal, procesos infecciosos, embarazo, fibrodisplasia de la arteria esplénica ${ }^{(2)}$.
La importancia del diagnóstico y el tratamiento del aneurisma de arteria esplénica radica en el riesgo de rotura, que aumenta significativamente más allá de los $2 \mathrm{~cm}$ de diámetro. La mortalidad después de la rotura varía desde el 25\% al 70\%, dependiendo de la patología subyacente ${ }^{(3)}$.

Varios tratamientos existen con respecto a los aneurismas esplénicos, como la embolización, la aneurismectomía o la esplenectomía por laparoscopia ${ }^{(4)}$.

\section{PRESENTACIÓN DE CASO CLÍNICO}

Paciente femenino de 66 años de edad presenta cuadro de dolor en epigastrio de 1 mes de evolución aproximadamente, tipo puntada, de moderada intensidad, con irradiación a la región dorsal. Al examen físico presenta un abdomen doloroso a la palpación profunda en epigastrio, sin defensa ni signos de irritación peritoneal.

Se solicita estudios complementarios, donde la analítica laboratorial se encuentra dentro de los parámetros normales, la ecografía abdominal documento una imagen sacular calcificada de aproximadamente $2 \mathrm{~cm}$ a nivel del hilio esplénico.

Se solicita una tomografía axial computarizada con contraste, donde se visualiza en la región del hilio esplénico en su porción distal una dilatación sacular con calcificación concéntrica que mide 21 x 16 mm, en íntima relación con la cola del páncreas.

Se indica cirugía electiva, la operación realizada fue una esplenopancreatectomia distal videolaparoscópica, en la cual se constata sobre la cola del páncreas una lesión de consistencia pétrea de dimensiones $3 \times 2 \mathrm{~cm}$, se realiza dos suturas con endogia vascular carga blanca en los vasos esplénicos y en la cola del páncreas.

1. Jefe de sala, Hospital Nacional de Itaugua, Paraguay

2. Residente del Segundo Año de Cirugía General

3. Jefe del Servicio de Cirugía Vascular, Hospital Nacional de Itaugua, Paraguay

4. Residente del Segundo Año de Cirugía General

Autor Correspondiente: Dr. Robert Andrés Ayala Giménez - Email: robandy93@hotmail.com

Recibido 25/03/2020 - Aceptado: 20/04/2020

Este es un artículo publicado en acceso abierto bajo una licencia Creative Commons 


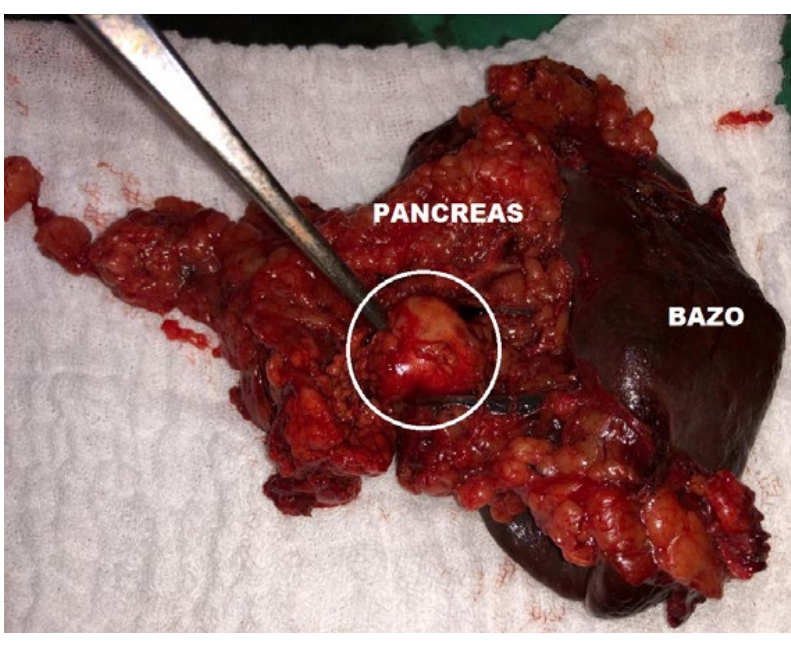

Ilustración 1.

\section{Informe de anatomía patológica:}

La lesión mide $1,5 \mathrm{~cm}$ y muestra paredes adelgazadas y la intima con una placa de capuchón delgado con núcleo blando y calcificación distrófica extensa en "cascara de huevo", dicho informe confirma el diagnostico de aneurisma arterosclerotico.

\section{DISCUSIÓN}

En este informe se describe un caso de aneurisma sintomático de la arteria esplénica, cuya evaluación imagenologica constató una imagen sacular mayor a dos centímetros por el cual fue preceptivo tratamiento quirúrgico. Actualmente está en proceso de revisión el procedimiento de abordaje terapéutico de esta patología. Si bien parece que la embolización sería el procedimiento de elección en casos asintomáticos, el tamaño del aneurisma y la tortuosidad de la arteria son factores que limitan el acceso vascular.

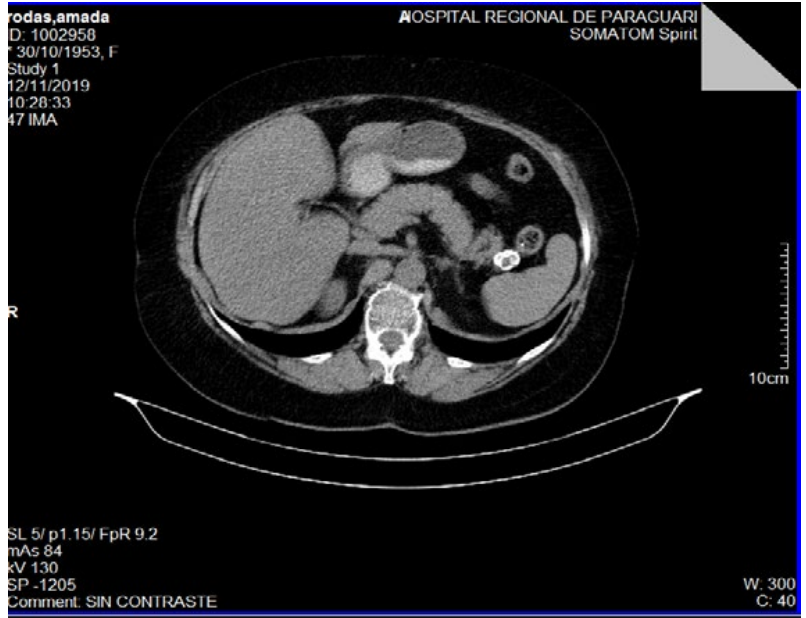

Ilustración 2.

\section{REFERENCIAS BIBLIOGRÁFICAS}

1. Larraín de la C D, Fava P M, Espinoza G R.. Aneurisma de la arteria esplénica: Diagnóstico diferencial y alternativas terapéuticas. Revista médica de Chile, 2005; 133(8): 943-6. Doi: 10.4067/S0034-98872005000800011.

2. Figueroa $B G$, Campos $G$ A, Rios $M$ P, Vásquez $G$ V. Aneurisma esplénico. Rev Chil Cir [Internet]. 2013 Dic [citado 2020 Feb 29] ; 65(6): 534-536. Disponible en: https://scielo.conicyt.cl/scielo.php?script=sci_ arttexterpid $=S 0718-4$.

3. Rivera A MA, Bravo F JI, Marino C CU, Tobar M JC. Resección de aneurisma de arteria esplénica por vía laparoscópica conservando el bazo. Rev Chil Cir [Internet]. 2011 Oct [citado $2020 \mathrm{Feb} 29$ ] ; 63(5): 524-6.

4. Abad C, Montesdeoca-Cabrera D, Sáez-Guzmán T. Aneurisma de la arteria esplénica. Revisión de dos casos intervenidos quirúrgicamente. An. Med. Interna (Madrid) 2006; 23(3) 